\title{
ORGAN WEIGHTS AND BODY COMPOSITION OF PARTURIENT AND LACTATING MICE, AND THEIR YOUNG, AT $21^{\circ} \mathrm{C}$ AND $-3^{\circ} \mathrm{C}$
}

\author{
S. A. BARNETT AND E. M. WIDDOWSON \\ Zoology Department, Glasgow University, and \\ Dunn Nutritional Laboratory, Cambridge
}

(Received 13th August 1970)

\begin{abstract}
Summary. Four classes of A2G/Tb mice were studied: (i) controls kept in an environmental temperature of $21^{\circ} \mathrm{C}$; (ii) mice transferred at mating from 21 to $-3^{\circ} \mathrm{C}$; (iii) mice of the first generation reared at $-3^{\circ} \mathrm{C}$; (iv) mice of the twenty-fifth to the twenty-ninth generations of a stock kept permanently at $-3^{\circ} \mathrm{C}$. Of each class, some were killed, with their litters, at either first or second parturition, and some on the 10th day of either the first or second lactation. Litters kept for 10 days were reduced to four young at birth.

The females at their first parturition were compared with virgins of a previous study. Pregnancy was accompanied by increase in the relative weight of heart, liver and stomach, and in the length of the small intestine; but the small intestine lost weight, and there was no change in kidney weight. The percentage of collagen and calcium in the body declined, but the absolute amount of nitrogen in the body increased.

During lactation, the liver and stomach, but not the heart, increased in relative weight still further; and the weight of the small intestine also rose. The percentage of fat and calcium in the body declined.

The relative weights of the heart, kidneys and small intestine were higher in the cold environment than at $21^{\circ} \mathrm{C}$, but liver weight was not affected. The proportion of fat, nitrogen and collagen in the body was lower in the cold.

The young had a much higher proportion of fat in their bodies at 10 days after birth than the neonates. They also contained more collagen and calcium and less water per unit body weight. The main effect of cold on the young was a higher fat content at birth.
\end{abstract}

\section{INTRODUGTION}

Pregnancy and lactation are especially exacting tests of cold-adaptation since, of all normal conditions, they require the highest rates of metabolic turnover. To maintain these rates, the functional capacity of certain organs must be increased. Accordingly, we have studied the effects of three kinds of exposure to a cold environment on the organ weights and body composition of parturient 
and lactating female mice and their young. Our findings illustrate the responses of a number of tissues during physiological adaptation to a double strain on bodily resources.

\section{METHODS}

\section{The mice and their environment}

The mice were of the highly inbred strain, $A 2 G / T b$, originally acquired as A2G from Glaxo Laboratories. Controls were kept in a temperature-regulated room at about $21^{\circ} \mathrm{C}$, and were of the thirty-seventh to the forty-fourth generations bred in Glasgow. The room used for experimental groups was kept at $-3^{\circ} \mathrm{C}$, with a differential of less than $1^{\circ} \mathrm{C}$ above and below this temperature. Every $6 \mathrm{hr}$, the temperature rose briefly to just below $0^{\circ} \mathrm{C}$ during automatic defrosting. There were also brief rises each morning when work work was going on. Once a week, when cages were cleaned, there was a more prolonged rise, sometimes above $0^{\circ} \mathrm{C}$. In both rooms, there was a 12-hr light-dark cycle. There was no control of humidity.

There were three classes of experimental mice. (i) The transferred pairs were the young of controls; they were reared at $21^{\circ} \mathrm{C}$, and transferred on mating to $-3^{\circ} \mathrm{C}$. (ii) The new stock were the offspring of transferred mice, that is, they were of the first generation reared in the cold. (iii) The old stock were from a colony which had been bred continuously at $-3^{\circ} \mathrm{C}$ for twenty-five to twentynine generations. All pairs were litter mates; the litters were separated into groups of like sex at the age of 5 weeks; pairs were mated at 10 weeks and thereafter remained together throughout the experiment. The controls, reared at $21^{\circ} \mathrm{C}$, constituted a fourth class. Each class was divided into four subclasses: females killed (i) at the birth of, or (ii) 10 days after the birth of their first litters, or (iii) at the birth of, or (iv) 10 days after the birth of their second litters. 'At birth' signifies litters found newly born on inspection of mated pairs at about 10.00 hours. 'Ten days' signifies 10 days after discovery of a new litter. Litters killed at birth were weighed and used as a whole for analysis. Litters to be kept to 10 days were reduced to four young at birth, so that conditions in the nest should be as uniform as possible. A pair whose second litter was to be used was allowed to rear the first litter to the age of 3 weeks. This sometimes required the female to provide milk for one litter during the gestation of a second.

The mice were kept in standard metal cages of the 'shoe box' type, $35 \times 10 \times 10$ $\mathrm{cm}$ high, with wire lids. The floor of each cage was covered with sawdust, and there was also cotton wool bedding. Conditions in such cages, in both environmental temperatures, have been described by Barnett (1956). There was never any sign of cold injury.

All mice had Diet 41 (Bruce \& Parkes, 1949) supplied in excess. At $21^{\circ} \mathrm{C}$, they had water at all times but, at $-3^{\circ} \mathrm{C}$, they had ice blocks which they licked; mice given water in this way have the same breeding performance as those which receive it in open jars in which it is allowed to freeze (Stoddart, 1966).

\section{Techniques}

The mice were killed with ether and weighed to the nearest $0 \cdot 1 \mathrm{~g}$. Each 
female was skinned and the skin, with hair, was weighed after removal of adherent fat and muscle. The liver, kidneys, spleen and heart were removed and weighed. The gastrointestinal tract from below the diaphragm was removed. The stomach was emptied and weighed. The small intestine was removed, laid out on a large sheet of paper and measured with a millimetre rule; it was then emptied and weighed. The large intestine, including the caecum, was also emptied and weighed. The uterus was removed and weighed.

The organs were returned to the rest of the skinned body, and the whole was dried at $95^{\circ} \mathrm{C}$ to a constant weight. To remove the fat, the dried body was covered with light petroleum (b.p. 40 to $60^{\circ} \mathrm{C}$ ) and left to stand overnight at room temperature. The petroleum was decanted, and the process repeated until the extract was colourless. Fat was taken as the difference between dry weight and fat-free dry weight. The dry fat-free residue was ground in a Culatti hammer mill and the powder sampled and analysed for total nitrogen, collagen, calcium and phosphorus (Dickerson, 1962). The skin was weighed and dried to a constant weight. Subsequent treatment of the skin was the same as that for the carcass.

The young were killed with ether. Their stomachs were emptied, and the whole litter was dried at $95^{\circ} \mathrm{C}$ to constant weight. Fat was removed as described above, and the residue analysed for nitrogen, collagen and calcium.

\section{Statistical analysis}

Statistical analyses were carried out by a KDF9 computer. Means and standard errors of organ weights were calculated, both for absolute values and also for the values relative to $100 \mathrm{~g}$ body weight. Relative organ weights are based on 'empty' body weight, that is, total weight minus weight of gut contents. Student's $t$ test (two-tailed) was used for comparisons between means. Wherever a statement is made about the significance of differences between means of organ weights, it is based on relative weights. To check that these are valid, and not merely a result of differences in body weight between classes, regressions of organ weights on body weight were calculated within classes; hardly any of these was statistically significant and so covariance analysis was not required (Angervall \& Carlström, 1963).

\section{RESULTS}

\section{General}

An overview of our findings is given in Tables 1, 19 and 20. For some organs and substances, there are comparable figures from previous work on virgin females aged 16 weeks (Barnett \& Widdowson, 1965); Table 1 summarizes the differences between the virgins and the females of the present work at the end of their first pregnancy when they were about the same age as the virgins. Since no virgins were studied immediately after transfer to the cold environment, only three classes can be compared. The original findings from the previous study were no longer available, and so no statistical analysis of the differences is possible; we therefore give only percentage differences.

All tables, except Tables 1, 19 and 20, are arranged on the 'diallele' system. 
TABLE 1

GOMPARISON OF PRIMIPAROUS MICE WITH VIRGIN FEMALES

\begin{tabular}{l|c|c|c}
\hline & & \multicolumn{2}{|c}{$-3^{\circ} C$} \\
\cline { 2 - 3 } & $21^{\circ} C$ & $\begin{array}{c}\text { Generation } 1 \\
\text { (new stock) }\end{array}$ & $\begin{array}{c}\text { Generations } 25 \text { to } 29 \\
\text { (old stock) }\end{array}$ \\
\hline Body weight & +11 & +5 & +13 \\
Heart weight & +121 & +114 & +65 \\
Liver weight & +90 & +49 & +59 \\
Kidney weight & -1 & +1 & -2 \\
Stomach weight & +25 & +6 & +19 \\
Small intestine: weight & -17 & -30 & -14 \\
& +20 & +16 & +15 \\
Spleen weight & +8 & +7 & +55 \\
Body fat & -4 & +16 & 0 \\
Water (carcass) & +4 & +2 & +2 \\
$\quad$ (skin) & 0 & -7 & +3 \\
Nitrogen (carcass) & +2 & 0 & +2 \\
Collagen (carcass) & +10 & +23 & +6 \\
$\quad$ (skin) & -22 & -13 & -24 \\
Calcium (carcass) & -31 & -40 & -45 \\
& -35 & -35 & -38 \\
\hline
\end{tabular}

The figures represent percentage change in relative weights, resulting from pregnancy.

Reading across gives the effect of reproductive state; reading down shows the effects of different kinds of cold exposure.

Numbers of mice and mean body weights are given in Table 2. The mice at $21^{\circ} \mathrm{C}$ were consistently heavier than those of any of the classes at $-3^{\circ} \mathrm{C}$, but the differences between them and the mice of long ancestry in the cold were small. The mice of the first generation reared in the cold were generally the lightest. This conforms with earlier observations (reviewed by Barnett, 1965).

TABLE 2

NUMBERS OF FEMALE MIGE AND THEIR BODY WEIGHTS

\begin{tabular}{|c|c|c|c|c|c|}
\hline \multirow[b]{2}{*}{$21^{\circ} \mathrm{C}$} & \multirow[b]{2}{*}{$\begin{array}{l}\text { No. of mice } \\
\text { B.wt (g) }\end{array}$} & \multicolumn{2}{|c|}{$\begin{array}{l}\text { After litter } 1 \\
0 \text { days } \quad 10 \text { days }\end{array}$} & \multicolumn{2}{|c|}{$\begin{array}{l}\text { After litter } 2 \\
0 \text { days } \quad 10 \text { days }\end{array}$} \\
\hline & & $\begin{array}{c}13 \\
27 \cdot 2 \pm 1 \cdot 1\end{array}$ & $\begin{array}{c}14 \\
27 \cdot 8 \pm 1 \cdot 1\end{array}$ & $\begin{array}{c}10 \\
28 \cdot 4 \pm 0 \cdot 2\end{array}$ & $\stackrel{11}{30 \cdot 6 \pm 1 \cdot 0}$ \\
\hline $21 \rightarrow-3^{\circ} \mathrm{C}$ & $\begin{array}{l}\text { No. of mice } \\
\text { B.wt }(\mathrm{g})\end{array}$ & $\begin{array}{c}13 \\
24 \cdot 6 \pm 0 \cdot 5\end{array}$ & $\begin{array}{c}16 \\
27 \cdot 2 \pm 0 \cdot 5\end{array}$ & $\begin{array}{c}10 \\
26 \cdot 9 \pm 1 \cdot 1\end{array}$ & $\begin{array}{c}10 \\
23 \cdot 7 \pm 1 \cdot 7\end{array}$ \\
\hline$-3^{\circ} \mathrm{C}$, Generation 1 & $\begin{array}{l}\text { No. of mice } \\
\text { B.wt }(\mathrm{g})\end{array}$ & $22 \cdot 9 \stackrel{9}{ \pm} 0.5$ & $\begin{array}{c}6 \\
23 \cdot 9^{ \pm}\end{array}$ & $\begin{array}{c}11 \\
25 \cdot 5 \pm 0.9\end{array}$ & $\begin{array}{c}12 \\
24 \cdot 2 \pm 1 \cdot 9\end{array}$ \\
\hline$-3^{\circ} \mathrm{C}$, Generations 25 to 29 & $\begin{array}{l}\text { No. of mice } \\
\text { B.wt }(\mathbf{g})\end{array}$ & $\begin{array}{c}10 \\
26 \cdot 2 \pm 0 \cdot 8\end{array}$ & $\frac{9}{26 \cdot 6 \pm 0.8}$ & $\begin{array}{c}10 \\
27 \cdot 9 \pm 0.7\end{array}$ & $\begin{array}{c}9 \\
29 \cdot 3 \pm 0.9\end{array}$ \\
\hline
\end{tabular}

Values expressed as means \pm S.E. 
TABle 3

HEART WEIGHTS OF FEMALE MICE

\begin{tabular}{|c|c|c|c|c|}
\hline & & $\begin{array}{l}\text { After litter } 1 \\
0 \text { days } 10 \text { days }\end{array}$ & \multicolumn{2}{|c|}{$\begin{array}{l}\text { After litter } 2 \\
0 \text { days } 10 \text { days }\end{array}$} \\
\hline $21^{\circ} \mathrm{C}$ & $\begin{array}{l}\mathrm{mg} \\
\mathrm{g} / 100 \mathrm{~g} \text { b.wt }\end{array}$ & $\begin{array}{cc}278 \pm 27 & 276 \pm 23 \\
1.07 \pm 0.03 & 0.99 \pm 0.03\end{array}$ & $\begin{array}{l}313 \pm 37 \\
1.07 \pm 0.04\end{array}$ & $\begin{array}{l}293 \pm 15 \\
0.97 \pm 0.04\end{array}$ \\
\hline $21 \rightarrow-3^{\circ} \mathrm{C}$ & $\begin{array}{l}\mathrm{mg} \\
\mathrm{g} / 100 \mathrm{~g} \text { b.wt }\end{array}$ & $\begin{array}{cc}322 \pm 29 & 329 \pm 23 \\
1.28 \pm 0.06 & 1.23 \pm 0.04\end{array}$ & $\begin{array}{l}342 \pm 39 \\
1 \cdot 22 \pm 0.05\end{array}$ & $\begin{array}{l}352 \pm 45 \\
1 \cdot 50 \pm 0.07\end{array}$ \\
\hline$-3^{\circ} \mathrm{C}$, Generation 1 & $\mathrm{mg} / 100 \mathrm{~g} \mathrm{b.wt}$ & $\begin{array}{cc}311 \pm 40 & 317 \pm 65 \\
1.34 \pm 0.04 & 1.38 \pm 0.14\end{array}$ & $\begin{array}{l}322 \pm 35 \\
1 \cdot 30 \pm 0.05\end{array}$ & $\begin{array}{l}332 \pm 31 \\
1 \cdot 38 \pm 0 \cdot 07\end{array}$ \\
\hline$-3^{\circ} \mathrm{C}$, Generations 25 to 29 & $\begin{array}{l}\mathrm{mg} \\
\mathrm{g} / 100 \mathrm{~g} \mathrm{~b} . w \mathrm{t}\end{array}$ & $\begin{array}{cc}302 \pm 35 & 333 \pm 45 \\
1 \cdot 15 \pm 0.05 & 1 \cdot 26 \pm 0.09\end{array}$ & $\begin{array}{l}356 \pm 42 \\
1 \cdot 24 \pm 0.04\end{array}$ & $\begin{array}{l}382 \pm 57 \\
1 \cdot 32 \pm 0.12\end{array}$ \\
\hline
\end{tabular}

Values expressed as means \pm S.E. Numbers of mice as in Table 2.

\section{Weights of organs}

The relative heart weight of primiparous females was about twice that of corresponding virgins. There was little evidence of further enlargement during lactation or during the second reproductive cycle (Table 3 ). The hearts of mice of all groups in the cold were larger, absolutely and relatively, than those of the corresponding control groups.

The relative weight of the liver of primiparous mice at $21^{\circ} \mathrm{C}$ averaged nearly twice that of the control virgins; this accords with the observations of Peters, Krijnen \& Boyd (1967) on rats. At $-3^{\circ} \mathrm{G}$ the difference was less but still marked. There was evidence of a further rise during first lactation; this too confirms previous work on rats (Kennedy, Pearce \& Parrott, 1958; Peters \& Krijnen, 1966). But during second pregnancy and lactation relative liver weight underwent no further increase, and even tended to decline, especially at $21^{\circ} \mathrm{G}$ (Table 4). The livers of the mice at $-3^{\circ} \mathrm{C}$ were not consistently larger than those of the corresponding controls. Hence the enlargement resulting from pregnancy was not enhanced in the cold environment.

\section{TABLE 4}

LIVER WEIGHTS OF FEMALE MICE

\begin{tabular}{|c|c|c|c|c|}
\hline & & $\begin{array}{l}\text { After litter } 1 \\
0 \text { days } \quad 10 \text { days }\end{array}$ & $\begin{array}{l}\text { After } \\
0 \text { days }\end{array}$ & $\begin{array}{l}\text { litter } 2 \\
\quad 10 \text { days }\end{array}$ \\
\hline $21^{\circ} \mathrm{C}$ & $g \mathrm{~g} / 100 \mathrm{~g}$ b.wt & $\begin{array}{ll}2.37 \pm 0.24 & 2.71 \pm 0.23 \\
8.49 \pm 0.21 & 9.63 \pm 1.07\end{array}$ & $\begin{array}{l}2 \cdot 74 \pm 0.33 \\
9 \cdot 54 \pm 0.39\end{array}$ & $\begin{array}{l}2 \cdot 68 \pm 0 \cdot 16 \\
8 \cdot 17 \pm 0 \cdot 25\end{array}$ \\
\hline $21 \rightarrow-3^{\circ} \mathrm{C}$ & $\begin{array}{l}\mathrm{g} \\
\mathrm{g} / 100 \mathrm{~g} \text { b.wt }\end{array}$ & $\begin{array}{ll}1.93 \pm 0.19 & 2.51 \pm 0.18 \\
7.64 \pm 0.64 & 9.60 \pm 0.51\end{array}$ & $\begin{array}{l}2 \cdot 38 \pm 0.29 \\
8 \cdot 46 \pm 0.13\end{array}$ & $\begin{array}{l}1.99 \pm 0.27 \\
8 \cdot 55 \pm 0 \cdot 11\end{array}$ \\
\hline$-3^{\circ} \mathrm{C}$, Generation 1 & $\begin{array}{l}\mathrm{g} \\
\mathrm{g} / 100 \mathrm{~g} \text { b.wt }\end{array}$ & $\begin{array}{rr}2.01 \pm 0.27 & 2.39 \pm 0.53 \\
8.29 \pm 0.43 & 10.05 \pm 0.51\end{array}$ & $\begin{array}{l}2 \cdot 27 \pm 0.24 \\
9 \cdot 21 \pm 0.45\end{array}$ & $\begin{array}{l}2 \cdot 07 \pm 0 \cdot 26 \\
8 \cdot 80 \pm 0.68\end{array}$ \\
\hline$-3^{\circ} \mathrm{C}$, Generations 25 to 29 & $\stackrel{g}{g / 100 ~ g ~ b . w t ~}$ & $\begin{array}{ll}2.41 \pm 0.28 & 2.54 \pm 0.33 \\
8.96 \pm 0.35 & 9.65 \pm 0.32\end{array}$ & $\begin{array}{l}2 \cdot 66 \pm 0.32 \\
9 \cdot 66 \pm 0.18\end{array}$ & $\begin{array}{l}2 \cdot 63 \pm 0 \cdot 34 \\
8 \cdot 83 \pm 0 \cdot 20\end{array}$ \\
\hline
\end{tabular}

Values expressed as means \pm S.E. Numbers of mice as in Table 2. 
TABLE 5

KIDNEY WEIGHTS OF FEMALE MIGE

\begin{tabular}{|c|c|c|c|c|c|}
\hline \multirow[b]{2}{*}{$21^{\circ} \mathrm{C}$} & \multirow[b]{2}{*}{$\begin{array}{l}\mathrm{mg} \\
\mathrm{mg} / 100 \mathrm{~g} \text { b.wt }\end{array}$} & \multicolumn{2}{|c|}{$\begin{array}{c}\text { After litter } 1 \\
0 \text { days } \quad 10 \text { days }\end{array}$} & \multicolumn{2}{|c|}{$\begin{array}{c}\text { After litter } 2 \\
0 \text { days } \quad 10 \text { days }\end{array}$} \\
\hline & & $\begin{array}{l}412 \pm 40 \\
1 \cdot 47 \pm 0 \cdot 04\end{array}$ & $\begin{array}{c}465 \pm 39 \\
1.67 \pm 0.06\end{array}$ & $\begin{array}{c}428 \pm 71 \\
1.67 \pm 0.09\end{array}$ & $\begin{array}{c}477 \pm 27 \\
1 \cdot 44 \pm 0.03\end{array}$ \\
\hline $21 \rightarrow-3^{\circ} \mathrm{C}$ & $\begin{array}{l}\mathrm{mg} \\
\mathrm{mg} / 100 \mathrm{~g} \text { b.wt }\end{array}$ & $\begin{array}{c}439 \pm 54 \\
2 \cdot 00 \pm 0 \cdot 07\end{array}$ & $\begin{array}{c}558 \pm 38 \\
2.09 \pm 0.06\end{array}$ & $\begin{array}{c}557 \pm 63 \\
2 \cdot 02 \pm 0 \cdot 11\end{array}$ & $\begin{array}{c}573 \pm 84 \\
2 \cdot 55 \pm 0 \cdot 23\end{array}$ \\
\hline$-3^{\circ} \mathrm{C}$, Generation 1 & $\begin{array}{l}\mathrm{mg} \\
\mathrm{mg} / 100 \mathrm{~g} \text { b.wt }\end{array}$ & $\begin{array}{c}484 \pm 64 \\
2 \cdot 02 \pm 0.06\end{array}$ & $\begin{array}{c}551 \pm 115 \\
2 \cdot 35 \pm 0 \cdot 14\end{array}$ & $\begin{array}{c}547 \pm 62 \\
2.37 \pm 0.04\end{array}$ & $\begin{array}{c}558 \pm 56 \\
2 \cdot 43 \pm 0 \cdot 09\end{array}$ \\
\hline$-3^{\circ} \mathrm{C}$, Generations 25 to 29 & $\begin{array}{l}\mathrm{mg} \\
\mathrm{mg} / 100 \mathrm{~g} \text { b.wt }\end{array}$ & $\begin{array}{c}443 \pm 51 \\
1.69 \pm 0.04\end{array}$ & $\begin{array}{c}495 \pm 66 \\
1 \cdot 89 \pm 0.07\end{array}$ & $\begin{array}{l}473 \pm 79 \\
1.75 \pm 0.08\end{array}$ & $\begin{array}{l}525 \pm 71 \\
1 \cdot 77 \pm 0 \cdot 08\end{array}$ \\
\hline
\end{tabular}

Values expressed as means \pm S.E. Numbers of mice as in Table 2.

The relative weights of the kidneys of the primiparous mice were, by contrast, no greater than those of the corresponding virgins, except those of the first generation at $-3^{\circ} \mathrm{C}$; but they showed a consistent tendency to increase during first lactation (Table 5). Kidneys were heavier at $-3^{\circ} \mathrm{C}$ than at $21^{\circ} \mathrm{C}$. The effect of the cold environment on the kidneys was most marked among the transferred mice and those of the first generation at $-3^{\circ} \mathrm{C}$. The mice of long ancestry at $-3^{\circ} \mathrm{C}$ had consistently lower relative kidney weights than those of the other two groups in the cold : the differences of the four classes of Generations 25 to 29 from Generation 1 are all statistically significant $(P<0.001,0.02$, $0.001,0.001$ ).

The stomachs of primiparous mice were heavier than those of virgins. The figures in Table 6 suggest that lactation generally led to a further increase, but none of the differences reaches even the $1 \%$ level. Cold made little difference to the relative stomach weights of the parturient and lactating mice, though it caused higher stomach weights in virgins (Barnett \& Widdowson 1965). The small intestine presented a contrasting and complex picture. At the

TABLE 6

STOMACH WEIGHTS OF FEMALE MICE

\begin{tabular}{|c|c|c|c|c|c|}
\hline \multirow[b]{2}{*}{$21^{\circ} \mathrm{C}$} & \multirow[b]{2}{*}{$\begin{array}{l}\mathrm{mg} \\
\mathrm{g} / 100 \mathrm{~g} \text { b.wt }\end{array}$} & \multicolumn{2}{|c|}{$\begin{array}{l}\text { After litter } 1 \\
0 \text { days } \quad 10 \text { days }\end{array}$} & \multicolumn{2}{|c|}{$\begin{array}{l}\text { After litter } 2 \\
0 \text { days } \quad 10 \text { days }\end{array}$} \\
\hline & & $\begin{array}{l}199 \pm 22 \\
0.73 \pm 0.08\end{array}$ & $\begin{array}{c}226 \pm 19 \\
0.80 \pm 0.04\end{array}$ & $\begin{array}{l}255 \pm 32 \\
0.85 \pm 0.03\end{array}$ & $\begin{array}{c}293 \pm 14 \\
1.02 \pm 0 \cdot 10\end{array}$ \\
\hline $21 \rightarrow-3^{\circ} \mathrm{C}$ & $\begin{array}{l}\mathrm{mg} \\
\mathrm{g} / 100 \mathrm{~g} \text { b.wt }\end{array}$ & $\begin{array}{l}191 \pm 17 \\
0.73 \pm 0.03\end{array}$ & $\begin{array}{l}254 \pm 29 \\
1.06 \pm 0.21\end{array}$ & $\begin{array}{c}239 \pm 30 \\
0.82 \pm 0.05\end{array}$ & $\begin{array}{l}242 \pm 32 \\
1.07 \pm 0.07\end{array}$ \\
\hline$-3^{\circ} \mathrm{C}$, Generation $\mathrm{l}$ & $\mathrm{mg} / 100 \mathrm{~g}$ b.wt & $\begin{array}{l}207 \pm 32 \\
0 \cdot 80 \pm 0 \cdot 03\end{array}$ & $\begin{array}{c}230 \pm 49 \\
1 \cdot 01 \pm 0 \cdot 13\end{array}$ & $\begin{array}{c}202 \pm 22 \\
0.81 \pm 0.03\end{array}$ & $\begin{array}{l}248 \pm 30 \\
0 \cdot 98 \pm 0 \cdot 10\end{array}$ \\
\hline$-3^{\circ} \mathrm{C}$, Generations 25 to 29 & $\mathrm{mg}$ & $\begin{array}{l}224 \pm 27 \\
0.86 \pm 0.05\end{array}$ & $\begin{array}{c}240 \pm 32 \\
0.93 \pm 0.04\end{array}$ & $\begin{array}{l}246 \pm 30 \\
0.83 \pm 0.06\end{array}$ & $\begin{array}{l}241 \pm 38 \\
0.74 \pm 0.08\end{array}$ \\
\hline
\end{tabular}

Values expressed as means \pm S.E. Numbers of mice as in Table 2. 
TABLE 7

WEIGHTS AND LENGTHS OF SMALL INTESTINE OF FEMALE MIGE

\begin{tabular}{|c|c|c|c|c|c|}
\hline & & \multicolumn{2}{|c|}{ After litter 1} & \multicolumn{2}{|c|}{ After litter 2} \\
\hline & & 0 days & 10 days & 0 days & 10 days \\
\hline $21^{\circ} \mathrm{C}$ & $\begin{array}{l}\mathrm{mg} \\
\mathrm{g} / 100 \mathrm{~g} \text { b.wt } \\
\mathrm{mm}\end{array}$ & $\begin{array}{c}643 \pm 75 \\
2 \cdot 54 \pm 0 \cdot 16 \\
559 \pm 51\end{array}$ & $\begin{array}{c}1002 \pm 87 \\
3 \cdot 65 \pm 0 \cdot 22 \\
561 \pm 45\end{array}$ & $\begin{array}{c}736 \pm 115 \\
2 \cdot 86 \pm 0 \cdot 37 \\
685 \pm 77\end{array}$ & $\begin{array}{c}760 \pm 59 \\
2 \cdot 26 \pm 0 \cdot 16 \\
661 \pm 15\end{array}$ \\
\hline $21 \rightarrow-3^{\circ} \mathrm{C}$ & $\begin{array}{l}\mathrm{mg} \\
\mathrm{g} / 100 \mathrm{~g} \text { b.wt } \\
\mathrm{mm}\end{array}$ & $\begin{array}{l}843 \pm 79 \\
3 \cdot 34 \pm 0 \cdot 21 \\
592 \pm 50\end{array}$ & $\begin{array}{c}1193 \pm 95 \\
4 \cdot 63 \pm 0 \cdot 37 \\
601 \pm 41\end{array}$ & $\begin{array}{l}604 \pm 81 \\
2 \cdot 11 \pm 0 \cdot 17 \\
668 \pm 75\end{array}$ & $\begin{array}{c}767 \pm 113 \\
3 \cdot 59 \pm 0 \cdot 25 \\
614 \pm 79\end{array}$ \\
\hline$-3^{\circ} \mathrm{C}$, Generation 1 & $\begin{array}{l}\mathrm{mg} \\
\mathrm{g} / 100 \mathrm{~g} \text { b.wt } \\
\mathrm{mm}\end{array}$ & $\begin{array}{c}665 \pm 105 \\
3 \cdot 12 \pm 0 \cdot 36 \\
600 \pm 75\end{array}$ & $\begin{array}{c}883 \pm 208 \\
3 \cdot 73 \pm 0.35 \\
602 \pm 123\end{array}$ & $\begin{array}{c}701 \pm 90 \\
2 \cdot 85 \pm 0 \cdot 13 \\
648 \pm 68\end{array}$ & $\begin{array}{c}884 \pm 110 \\
3 \cdot 90 \pm 0 \cdot 33 \\
653 \pm 60\end{array}$ \\
\hline$-3^{\circ} \mathrm{C}$, Generations 25 to 29 & $\begin{array}{l}\mathrm{mg} \\
\mathrm{g} / 100 \mathrm{~g} \text { b.wt } \\
\mathrm{mm}\end{array}$ & $\begin{array}{c}900 \pm 113 \\
3 \cdot 74 \pm 0 \cdot 11 \\
615 \pm 69\end{array}$ & $\begin{array}{c}989 \pm 172 \\
3.91 \pm 0 \cdot 45 \\
630 \pm 80\end{array}$ & $\begin{array}{c}760 \pm 106 \\
2 \cdot 87 \pm 0 \cdot 28 \\
659 \pm 79\end{array}$ & $\begin{array}{c}848 \pm 141 \\
3 \cdot 00 \pm 0 \cdot 29 \\
700 \pm 88\end{array}$ \\
\hline
\end{tabular}

Values expressed as means \pm S.E. Numbers of mice as in Table 2.

end of first pregnancy absolute and relative weights had declined from those of virgins of all classes, but length had increased; the small intestine again declined in weight during second pregnancy, but it continued to lengthen (Table 7): hence weight per unit length was consistently low at parturition; this must have been due to thinning of the gut wall. The intestine weight (but not length) of most classes increased during lactation, as was to be expected from previous work (Fell \& Campbell, 1964). Hence the weight (absolute or relative) of the small intestine fluctuated with reproductive state, but absolute length tended to rise throughout. Whether the change in length was related to age rather than parity cannot be determined on this evidence. The effect of cold on the small intestine was usually a higher relative weight and, during first pregnancy and lactation, greater length also.

\section{TABLE 8}

WEIGHTS OF LARGE INTESTINE OF FEMALE MICE

\begin{tabular}{|c|c|c|c|c|c|}
\hline \multirow[b]{2}{*}{$21^{\circ} \mathrm{C}$} & \multirow[b]{2}{*}{$\mathrm{mg}_{\mathrm{g} / \mathrm{l} 00 \mathrm{~g} \text { b.wt }}$} & \multicolumn{2}{|c|}{$\begin{array}{c}\text { After litter } 1 \\
0 \text { days } \quad 10 \text { days }\end{array}$} & \multicolumn{2}{|c|}{$\begin{array}{l}\text { After litter } 2 \\
0 \text { days } \quad 10 \text { days }\end{array}$} \\
\hline & & $\begin{array}{l}442 \pm 45 \\
1 \cdot 68 \pm 0 \cdot 15\end{array}$ & $\begin{array}{l}609 \pm 50 \\
2 \cdot 14 \pm 0.07\end{array}$ & $\begin{array}{c}505 \pm 65 \\
1 \cdot 74 \pm 0 \cdot 13\end{array}$ & $\begin{array}{l}562 \pm 26 \\
1 \cdot 92 \pm 0 \cdot 12\end{array}$ \\
\hline $21 \rightarrow-3^{\circ} \mathrm{C}$ & 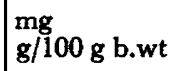 & $\begin{array}{l}473 \pm 50 \\
1 \cdot 73 \pm 0.09\end{array}$ & $\begin{array}{c}591 \pm 43 \\
2 \cdot 20 \pm 0 \cdot 06\end{array}$ & $\begin{array}{c}387 \pm 48 \\
1 \cdot 33 \pm 0.06\end{array}$ & $\begin{array}{l}408 \pm 59 \\
1 \cdot 78 \pm 0 \cdot 09\end{array}$ \\
\hline$-3^{\circ} \mathrm{C}$, Generation 1 & $\begin{array}{l}\mathrm{mg} \\
\mathrm{g} / 100 \mathrm{~g} \text { b.wt }\end{array}$ & $\begin{array}{l}431 \pm 66 \\
1 \cdot 99 \pm 0 \cdot 23\end{array}$ & $\begin{array}{l}414 \pm 85 \\
1 \cdot 79 \pm 0 \cdot 16\end{array}$ & $\begin{array}{c}333 \pm 39 \\
1 \cdot 23 \pm 0.09\end{array}$ & $\begin{array}{l}389 \pm 37 \\
1 \cdot 62 \pm 0 \cdot 07\end{array}$ \\
\hline$-3^{\circ} \mathrm{C}$, Generations 25 to 29 & $\begin{array}{l}\mathrm{mg} \\
\mathrm{g} / 100 \mathrm{~g} \text { b.wt }\end{array}$ & $\begin{array}{l}387 \pm 46 \\
1 \cdot 51 \pm 0 \cdot 11\end{array}$ & $\begin{array}{l}488 \pm 77 \\
1.94 \pm 0.19\end{array}$ & $\begin{array}{l}383 \pm 46 \\
1 \cdot 33 \pm 0.09\end{array}$ & $\begin{array}{c}435 \pm 58 \\
1 \cdot 49 \pm 0 \cdot 10\end{array}$ \\
\hline
\end{tabular}

Values expressed as means \pm S.E. Numbers of mice as in Table 2. 
TABLE 9

SPLEEN WEIGHTS OF FEMALE MICE

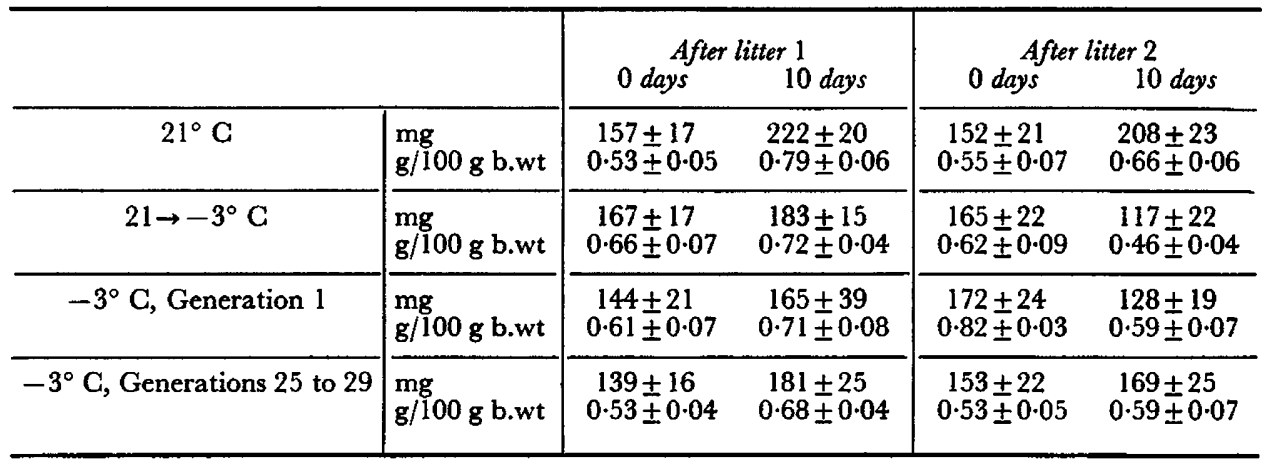

Values expressed as means \pm S.E. Numbers of mice as in Table 2 .

There are no figures for the large intestine of virgin mice. The relative weight of the large intestine usually rose during lactation (Table 8). The mice in the cold tended to have lighter large intestines than those of the controls, but the differences in relative weights were small and inconsistent.

The spleen of primiparous mice of long ancestry at $-3^{\circ} \mathrm{C}$ was much heavier than that of virgins. Peters et al. (1967) report a similar effect of pregnancy on the spleen of rats. At $21^{\circ} \mathrm{C}$ absolute and relative spleen weight increased during both lactations, but there was no consistent effect at $-3^{\circ} \mathrm{C}$ (Table 9). Nor was there any consistent effect of cold.

The relative weight of the uterus declined during lactation, except that of the controls with their second litter. It rose again during second pregnancy, but the lowest mean relative uterine weights recorded were those of all groups at $-3^{\circ} \mathrm{C}$ during second lactation (Table 10). Uterine weight tended to be lower at $-3^{\circ} \mathrm{C}$ than at $21^{\circ} \mathrm{C}$.

The figures of skin weights in Table 11 represent the weight of the fresh skin with its hair, but without fat. The weights, absolute or relative, were all

TABLE 10

UTERUS WEIGHTS OF MICE

\begin{tabular}{|c|c|c|c|c|c|}
\hline \multirow[b]{2}{*}{$21^{\circ} \mathrm{C}$} & \multirow[b]{2}{*}{$\begin{array}{l}\mathrm{mg} \\
\mathrm{g} / \mathrm{l} 00 \mathrm{~g} \text { b.wt }\end{array}$} & \multicolumn{2}{|c|}{$\begin{array}{l}\text { After litter } 1 \\
0 \text { days } \quad 10 \text { days }\end{array}$} & \multicolumn{2}{|c|}{$\begin{array}{c}\text { After litter } 2 \\
0 \text { days } \quad 10 \text { days }\end{array}$} \\
\hline & & $\begin{array}{c}664 \pm 66 \\
2 \cdot 55 \pm 0 \cdot 17\end{array}$ & $\begin{array}{c}553 \pm 69 \\
2 \cdot 03 \pm 0 \cdot 34\end{array}$ & $\begin{array}{c}576 \pm 79 \\
2 \cdot 05 \pm 0 \cdot 16\end{array}$ & $\begin{array}{c}665 \pm 197 \\
2 \cdot 24 \pm 0 \cdot 25\end{array}$ \\
\hline $21 \rightarrow-3^{\circ} \mathrm{C}$ & $\mathrm{mg} / 100 \mathrm{~g}$ b.wt & $\begin{array}{l}569 \pm 73 \\
1 \cdot 87 \pm 0 \cdot 30\end{array}$ & $\begin{array}{l}413 \pm 56 \\
1 \cdot 52 \pm 0 \cdot 28\end{array}$ & $\begin{array}{c}572+85 \\
2 \cdot 23 \pm 0 \cdot 21\end{array}$ & $\begin{array}{l}282 \pm 77 \\
1 \cdot 18 \pm 0.33\end{array}$ \\
\hline$-3^{\circ} \mathrm{C}$, Generation 1 & $\begin{array}{l}\mathrm{mg} \\
\mathrm{g} / 100 \mathrm{~g} \text { b.wt }\end{array}$ & $\begin{array}{c}422 \pm 72 \\
2 \cdot 02 \pm 0.25\end{array}$ & $\begin{array}{l}356 \pm 84 \\
1 \cdot 60 \pm 0.31\end{array}$ & $\begin{array}{c}524 \pm 70 \\
2 \cdot 15 \pm 0 \cdot 23\end{array}$ & $\begin{array}{l}240 \pm 74 \\
1 \cdot 15 \pm 0.42\end{array}$ \\
\hline$-3^{\circ} \mathrm{C}$, Generations 25 to 29 & $\mathrm{mg}$ & $\begin{array}{c}535 \pm 78 \\
1 \cdot 88 \pm 0 \cdot 22\end{array}$ & $\begin{array}{c}426 \pm 69 \\
1 \cdot 68 \pm 0 \cdot 21\end{array}$ & $\begin{array}{c}662 \pm 97 \\
2.03 \pm 0.23\end{array}$ & $\begin{array}{c}357 \pm 76 \\
1 \cdot 12 \pm 0 \cdot 20\end{array}$ \\
\hline
\end{tabular}

Values expressed as means \pm S.E. Numbers of mice as in Table 2. 
TABLE 11

WEIGHTS OF FAT-FREE SKINS OF FEMALE MICE

\begin{tabular}{|c|c|c|c|c|c|}
\hline \multirow[b]{2}{*}{$21^{\circ} \mathrm{C}$} & \multirow[b]{2}{*}{$\mathrm{g} / 100 \mathrm{~g}$ b.wt } & \multicolumn{2}{|c|}{$\begin{array}{l}\text { After litter } 1 \\
0 \text { days } \quad 10 \text { days }\end{array}$} & \multicolumn{2}{|c|}{$\begin{array}{l}\text { After litter } 2 \\
0 \text { days } 10 \text { days }\end{array}$} \\
\hline & & $\begin{array}{l}3 \cdot 2 \pm 0.31 \\
11 \cdot 4 \pm 0.2\end{array}$ & $\begin{array}{l}3 \cdot 3 \pm 0.28 \\
11 \cdot 3 \pm 0.4\end{array}$ & $\begin{array}{l}3.3 \pm 0.38 \\
11 \cdot 8 \pm 0.2\end{array}$ & $\begin{array}{l}3 \cdot 8 \pm 0 \cdot 41 \\
13 \cdot 4 \pm 0 \cdot 3\end{array}$ \\
\hline $21 \rightarrow-3^{\circ} \mathrm{C}$ & $\begin{array}{l}g \\
g / 100 g \text { b.wt }\end{array}$ & $\begin{array}{r}3 \cdot 2 \pm 0.32 \\
11.9 \pm 0.9\end{array}$ & $\begin{array}{l}3 \cdot 0 \pm 0.22 \\
11 \cdot 1 \pm 0.4\end{array}$ & $\begin{array}{r}3 \cdot 5 \pm 0 \cdot 41 \\
12 \cdot 4 \pm 0 \cdot 3\end{array}$ & $\begin{aligned} 3 \cdot 1 & \pm 0.45 \\
13 \cdot 0 & \pm 0 \cdot 3\end{aligned}$ \\
\hline$-3^{\circ} \mathrm{C}$, Generation 1 & $\mathrm{~g} / 100 \mathrm{~g}$ b.wt & $\begin{array}{l}3 \cdot 0 \pm 0.39 \\
12 \cdot 2 \pm 0.4 \\
\end{array}$ & $\begin{array}{l}3 \cdot 1 \pm 0 \cdot 63 \\
14 \cdot 2 \pm 2 \cdot 0\end{array}$ & $\begin{array}{c}3 \cdot 3 \pm 0.36 \\
13 \cdot 5 \pm 0.7 \\
\end{array}$ & $\begin{array}{l}3 \cdot 0 \pm 0 \cdot 45 \\
12 \cdot 6 \pm 0.5\end{array}$ \\
\hline$-3^{\circ} \mathrm{C}$, Generations 25 to 29 & $\mathrm{~g} / 100 \mathrm{~g}$ b.wt & $\begin{array}{r}3 \cdot 1 \pm 0 \cdot 36 \\
11 \cdot 6 \pm 0 \cdot 4\end{array}$ & $\begin{array}{r}3 \cdot 1 \pm 0.41 \\
12 \cdot 4 \pm 0 \cdot 7\end{array}$ & $\begin{aligned} & 3.4 \pm 0.38 \\
& 11.9 \pm 0.3\end{aligned}$ & $\begin{array}{c}3.7 \pm 0.47 \\
12.2 \pm 0.3\end{array}$ \\
\hline
\end{tabular}

Values expressed as means \pm S.E. Numbers of mice as in Table 2.

TABLE 12

FAT CONTENT OF FEMALE MICE

\begin{tabular}{c|rr|rr}
\hline & \multicolumn{2}{|c|}{ After litter 1} & \multicolumn{2}{c}{ After litter 2} \\
& \multicolumn{1}{|c}{0 days } & 10 days & \multicolumn{1}{c}{0 days } & 10 days \\
\hline $21^{\circ} \mathrm{C}$ & $13 \cdot 6 \pm 0.9$ & $9 \cdot 5 \pm 0 \cdot 1$ & $11 \cdot 0 \pm 0 \cdot 6$ & $12 \cdot 1 \pm 1 \cdot 2$ \\
$21 \rightarrow-3^{\circ} \mathrm{C}$ & $9 \cdot 3 \pm 0 \cdot 5$ & $9 \cdot 2 \pm 0 \cdot 8$ & $11 \cdot 4 \pm 1 \cdot 4$ & $5 \cdot 8 \pm 1 \cdot 0$ \\
$-3^{\circ} \mathrm{C}$, Generation 1 & $9 \cdot 9 \pm 0 \cdot 5$ & $7 \cdot 6 \pm 0 \cdot 1$ & $7 \cdot 2 \pm 0 \cdot 1$ & $7 \cdot 7 \pm 1 \cdot 3$ \\
$-3^{\circ} \mathrm{C}$, Generations 25 to 29 & $10 \cdot 9 \pm 0 \cdot 3$ & $10 \cdot 8 \pm 0 \cdot 6$ & $12 \cdot 3 \pm 0 \cdot 7$ & $10 \cdot 3 \pm 0.9$ \\
\hline
\end{tabular}

Numbers of mice in each class as in Table 2.

Fat content expressed as mean $\%$ b.wt \pm S.E.

TABLE 13

WATER CONTENT OF FAT-FREE CARCASS AND SKIN OF FEMALE MICE

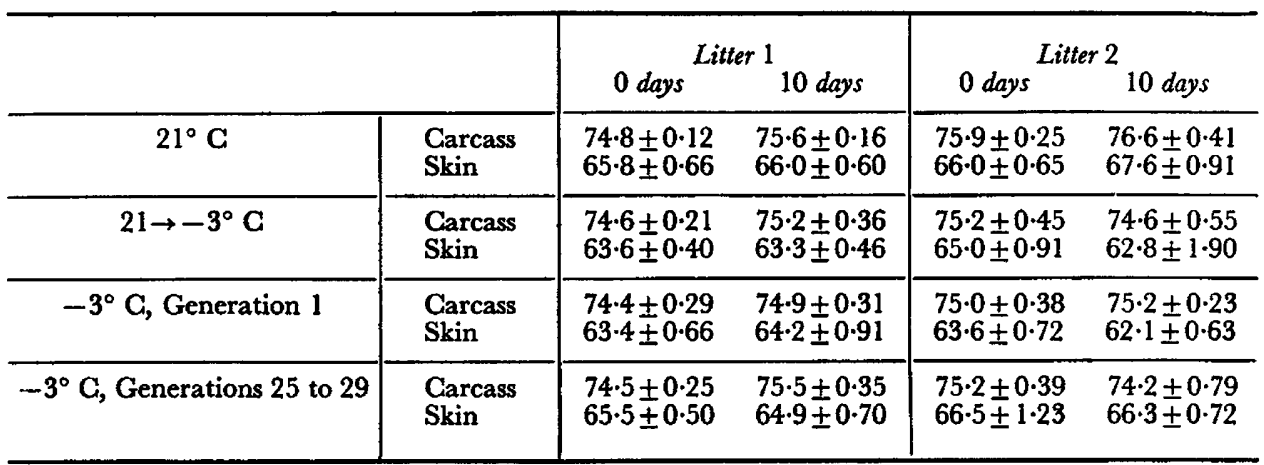

Numbers of mice in each class as in Table 2.

Values expressed as mean $\% \pm$ S.E. of water in fat-free carcass and skin. 


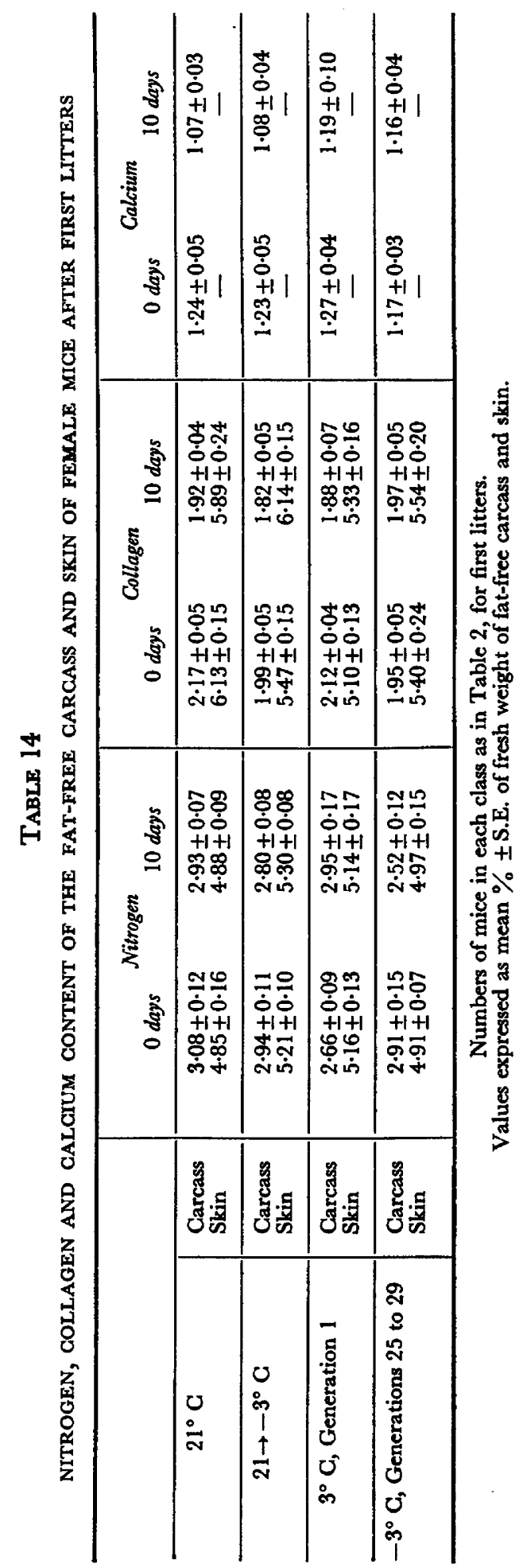


higher after first pregnancy than those given by Barnett \& Widdowson (1965) for skin plus hair of virgins. The relative weight of skin plus hair of parturient and lactating mice was not consistently altered either by reproductive state or by the cold environment.

\section{Chemical composition}

The percentage of fat in the primiparous mice was similar to that in virgin females. The figure tended to decline during first lactation but, except in the first generation at $-3^{\circ} \mathrm{C}$, was partly or wholly restored by the time of second parturition (Table 12). During second lactation the proportion of fat in the transferred mice again declined but it did not do so in the mice of the other groups.

TABLE 15

TOTAL NITROGEN, COLLAGEN AND GALGIUM IN THE BODIES OF FEMALE MICE

\begin{tabular}{|c|c|c|c|c|}
\hline & & Virgin* & Parturient $\dagger$ & Lactating $\dagger$ \\
\hline $21^{\circ} \mathrm{C}$ & $\begin{array}{l}\text { Nitrogen } \\
\text { Collagen } \\
\text { Calcium }\end{array}$ & $\begin{array}{l}0.53 \\
0.59 \\
0 \cdot 28\end{array}$ & $\begin{array}{l}0.84 \\
0 \cdot 70 \\
0 \cdot 28\end{array}$ & $\begin{array}{l}0.83 \\
0 \cdot 62 \\
0 \cdot 25\end{array}$ \\
\hline $21 \rightarrow-3^{\circ} \mathrm{C}$ & $\begin{array}{l}\text { Nitrogen } \\
\text { Collagen } \\
\text { Calcium }\end{array}$ & $\bar{z}$ & $\begin{array}{l}0.73 \\
0.56 \\
0.25\end{array}$ & $\begin{array}{l}0.74 \\
0.56 \\
0.23\end{array}$ \\
\hline$-3^{\circ} \mathrm{C}$, Generation 1 & $\begin{array}{l}\text { Nitrogen } \\
\text { Collagen } \\
\text { Calcium }\end{array}$ & $\begin{array}{l}0.43 \\
0.47 \\
0.26\end{array}$ & $\begin{array}{l}0.65 \\
0.54 \\
0 \cdot 24\end{array}$ & $\begin{array}{l}0.77 \\
0.56 \\
0.24\end{array}$ \\
\hline$-3^{\circ} \mathrm{C}$, Generations 25 to 29 & $\begin{array}{l}\text { Nitrogen } \\
\text { Collagen } \\
\text { Calcium }\end{array}$ & $\begin{array}{l}0.49 \\
0.53 \\
0.27\end{array}$ & $\begin{array}{l}0.75 \\
0.57 \\
0.24\end{array}$ & $\begin{array}{l}0.65 \\
0.56 \\
0 \cdot 23\end{array}$ \\
\hline
\end{tabular}

A fall in the proportion of fat in mice lactating at $21^{\circ} \mathrm{C}$ has also been observed by Pennycuik (1966); even when her mice were kept at $34^{\circ} \mathrm{C}$ there was some decline. There was a tendency for the mice at $-3^{\circ} \mathrm{C}$ to have a lower proportion of fat than those at $21^{\circ} \mathrm{C}$, but each class in the cold evidently had its own distinctive pattern of fat metabolism; in particular, the mice of long ancestry in the cold had consistently more fat per unit body weight than the other two classes at $-3^{\circ} \mathrm{C}$.

There was a slightly higher percentage of water, and hence a lower percentage of solids, in the fat-free carcass of all groups of primiparous mice than in virgins of the same class. The lower figure for solids corresponds to the lower proportion of collagen and calcium also found in the primiparous mice; this must reflect a lower relative weight of bone. There was no consistent effect of lactation or of second pregnancy on water content (Table 13). Nitrogen, expressed as a percentage of carcass weight, was unaffected by lactation, but carcass collagen and calcium tended to decline (Table 14). 
Further information on changes in the content of solids may be obtained from the absolute amounts present in the body. Table 15 compares the figures for virgins with those of pregnant and lactating mice at both temperatures: there was a substantial increase, even at $-3^{\circ} \mathrm{C}$, in the amount of nitrogen in the body during pregnancy; this was in addition to the nitrogen laid down in the foetuses. This confirms the observations of Spray (1950). By contrast, the figures for collagen show little change; and those for calcium show none. Hence it is the gain in body protein, not loss of calcium, which accounts for the lower concentration of calcium in the parturient female.

The controls had nearly always a higher concentration of nitrogen and collagen in their bodies, and of collagen in their skins, than the groups at $-3^{\circ} \mathrm{C}$, but almost the same proportion of calcium.

TABLE 16

LITTER SIZES AND WEIGHTS

\begin{tabular}{|c|c|c|c|c|c|}
\hline \multirow[b]{2}{*}{$21^{\circ} \mathrm{C}$} & \multirow[b]{2}{*}{$\begin{array}{l}\text { Young/litter } \\
\text { Wt (g) }\end{array}$} & \multicolumn{2}{|c|}{0 days ${ }^{\text {Litter } 1} 10$ days* } & \multicolumn{2}{|c|}{0 days ${ }^{\text {Litter } 2} 10$ days* } \\
\hline & & $\begin{array}{c}6.0 \pm 0.48 \\
(12) \\
8.5 \pm 0.53\end{array}$ & $\begin{array}{c}4 \cdot 0 \\
(11) \\
28 \cdot 4 \pm 1.06\end{array}$ & $\begin{array}{c}5 \cdot 5 \pm 1 \cdot 11 \\
(10) \\
8.4 \pm 1.69\end{array}$ & $\begin{array}{c}4.0 \\
(8) \\
26 \cdot 2 \pm 1.57\end{array}$ \\
\hline $21 \rightarrow-3^{\circ} \mathrm{C}$ & $\begin{array}{l}\text { Young/litter } \\
\text { Wt (g) }\end{array}$ & $\begin{array}{c}5.5 \pm 0.49 \\
(13) \\
8.3 \pm 0.66\end{array}$ & $\begin{array}{c}4 \cdot 0 \\
(11) \\
26 \cdot 8 \pm 1 \cdot 26\end{array}$ & $\begin{array}{c}6.0 \pm 0.77 \\
(10) \\
9 \cdot 8 \pm 1.28\end{array}$ & $\begin{array}{c}4 \cdot 0 \\
(5) \\
29 \cdot 3 \pm 2 \cdot 32\end{array}$ \\
\hline$-3^{\circ} \mathrm{C}$, Generation 1 & $\begin{array}{l}\text { Young/litter } \\
\text { Wt (g) }\end{array}$ & $\begin{array}{c}5 \cdot 2 \pm 0.81 \\
(9) \\
7 \cdot 5 \pm 1.12\end{array}$ & $\begin{array}{c}4 \cdot 0 \\
(3) \\
26 \cdot 6 \pm 1.84\end{array}$ & $\begin{array}{c}5.4 \pm 0.51 \\
(11) \\
7.9 \pm 0.70\end{array}$ & $\begin{array}{c}4.0 \\
(9) \\
23 \cdot 1 \pm 1 \cdot 37\end{array}$ \\
\hline$-3^{\circ} \mathrm{C}$, Generations 25 to 29 & $\begin{array}{l}\text { Young/litter } \\
\text { Wt (g) }\end{array}$ & $\begin{array}{c}5 \cdot 2 \pm 0.71 \\
(10) \\
8 \cdot 1 \pm 0.94\end{array}$ & $\begin{array}{c}4.0 \\
(7) \\
26 \cdot 6 \pm 1 \cdot 04\end{array}$ & $\begin{array}{c}6.2 \pm 0.75 \\
(10) \\
9 \cdot 2 \pm 0.96\end{array}$ & $\begin{array}{c}4 \cdot 0 \\
(7) \\
28 \cdot 4 \pm 2 \cdot 09\end{array}$ \\
\hline
\end{tabular}

Values expressed as means \pm S.E. Number of litters in parentheses.

* Wholly surviving litters only.

\section{Effects on young}

The observations on the newborn and 10-day young are summarized in Tables 16 to 18 . The increase in weight from birth to 10 days was accompanied by an increase in the proportion of body fat from $2.5 \%$, or less, to about $15 \%$. There were also increases in the concentration of nitrogen, collagen and calcium (Tables 17 and 18), and a corresponding decrease in water. These findings conform with those of Bailey, Kitts \& Wood (1960) on mice, and with those of Spray \& Widdowson (1950) and Widdowson \& Dickerson (1964) on a number of other species.

The cold environment had little effect on birth weight, the number of young born per litter, or on the weight of the four mice of each litter kept to 10 days (Table 16). The principal influence of cold on the composition of the young was a higher fat content at birth (Table 17). This unexpected finding applies to all three classes in the cold, and to both first and second litters. 
TABLE 17

WATER AND FAT CONTENT OF YOUNG MICE

\begin{tabular}{|c|c|c|c|c|c|}
\hline \multirow[b]{2}{*}{$21^{\circ} \mathrm{C}$} & \multirow[b]{2}{*}{$\begin{array}{l}\text { Water* } \\
\text { Fatf }\end{array}$} & \multicolumn{2}{|c|}{0 days ${ }^{\text {Litter } 1} 10$ days } & \multicolumn{2}{|c|}{0 days ${ }_{\text {Litter } 2} 10$ days } \\
\hline & & $\begin{array}{c}85.3 \pm 0.17 \\
(12) \\
0.9 \pm 0.27\end{array}$ & $\begin{array}{c}80 \cdot 0 \pm 2 \cdot 12 \\
(14) \\
17 \cdot 5 \pm 1 \cdot 78\end{array}$ & $\begin{array}{c}84.5 \pm 0.38 \\
(10) \\
1.3 \pm 0.34\end{array}$ & $\begin{array}{c}78 \cdot 6 \pm 0.62 \\
(10) \\
13 \cdot 5 \pm 1.50\end{array}$ \\
\hline $21 \rightarrow-3^{\circ} \mathrm{C}$ & $\begin{array}{l}\text { Water* } \\
\text { Fat } \dagger\end{array}$ & $\begin{array}{c}84.2 \pm 0.27 \\
(13) \\
2 \cdot 1 \pm 0.39\end{array}$ & $\begin{array}{c}79 \cdot 3 \pm 0.20 \\
(16) \\
17.7 \pm 0.75\end{array}$ & $\begin{array}{c}85.5 \pm 0.39 \\
(10) \\
2.1 \pm 0.50\end{array}$ & $\begin{array}{c}80 \cdot 2 \pm 0.76 \\
(\overline{9}) \\
19 \cdot 0 \pm 1.36\end{array}$ \\
\hline$-3^{\circ} \mathrm{C}$, Generation 1 & $\begin{array}{l}\text { Water* } \\
\text { Fat } \dagger\end{array}$ & $\begin{array}{c}84.0 \pm 0.35 \\
\left(\frac{9}{9}\right) \\
2.5 \pm 0.66\end{array}$ & $\begin{array}{c}79.6 \pm 0.09 \\
(6) \\
17.7 \pm 0.91\end{array}$ & $\begin{array}{c}84.6 \pm 0.30 \\
(11) \\
1.3 \pm 0.52\end{array}$ & $\begin{array}{c}79.8 \pm 0.23 \\
(12) \\
14.9 \pm 0.74\end{array}$ \\
\hline$-3^{\circ} \mathrm{C}$, Generations 25 to 29 & $\begin{array}{l}\text { Water* } \\
\text { Fat† }\end{array}$ & $\begin{array}{c}84 \cdot 3 \pm 0.21 \\
(10) \\
2 \cdot 0 \pm 0.50\end{array}$ & $\begin{array}{c}79.3 \pm 0.24 \\
(\overline{9}) \\
18 \cdot 2 \pm 0.81\end{array}$ & $\begin{array}{c}85 \cdot 1 \pm 0.17 \\
(10) \\
1 \cdot 6 \pm 0.25\end{array}$ & $\begin{array}{c}79 \cdot 5 \pm 0.44 \\
(\overline{9}) \\
17 \cdot 8 \pm 1.31\end{array}$ \\
\hline
\end{tabular}

Number of litters in parentheses.

* Expressed as mean $\% \pm$ S.E. of the fat-free body

$\dagger$ Expressed as mean $\% \pm$ S.E. of b.wt.

\section{DISCUSSION}

\section{Effects of pregnancy}

The greatest effects on organ weights and body composition were those associated with pregnancy. This is shown by comparing the virgins of the previous study (Barnett \& Widdowson, 1965) with the females at their first parturition (Tables 1 and 15). The relative weight of the heart doubled during pregnancy, in both environments. The relative weight of the liver, too, nearly doubled at $21^{\circ} \mathrm{C}$; at $-3^{\circ} \mathrm{C}$, the increase was about $50 \%$. Evidently, the increase in relative liver weight due to the cold environment and that due to pregnancy were not simply additive. By comparison, the increase in relative stomach weight was small. These processes of adaptive growth were accompanied by an increase of about $50 \%$ in the amount of nitrogen in the body.

There were two anomalies. First, despite the increase in food intake (Barnett \& Little, 1965), the weight of the kidneys was unaffected by pregnancy. Second, the small intestine of parturient mice was lighter than that of the virgins, though it evidently lengthened during pregnancy. Both these observations suggest the need for further histological and functional studies of these organs under various conditions of demand upon them.

\section{Effects of lactation}

Compared with those of pregnancy, the changes which accompanied lactation (Table 19) were small. The heart, whose weight increased so greatly in pregnancy, was evidently able to cope with the additional demands of lactation without further enlargement. On the other hand, the liver enlarged further during first lactation, and the weight of the small intestine, but not its length, also increased. These changes correspond to the steep rise in food consumption 


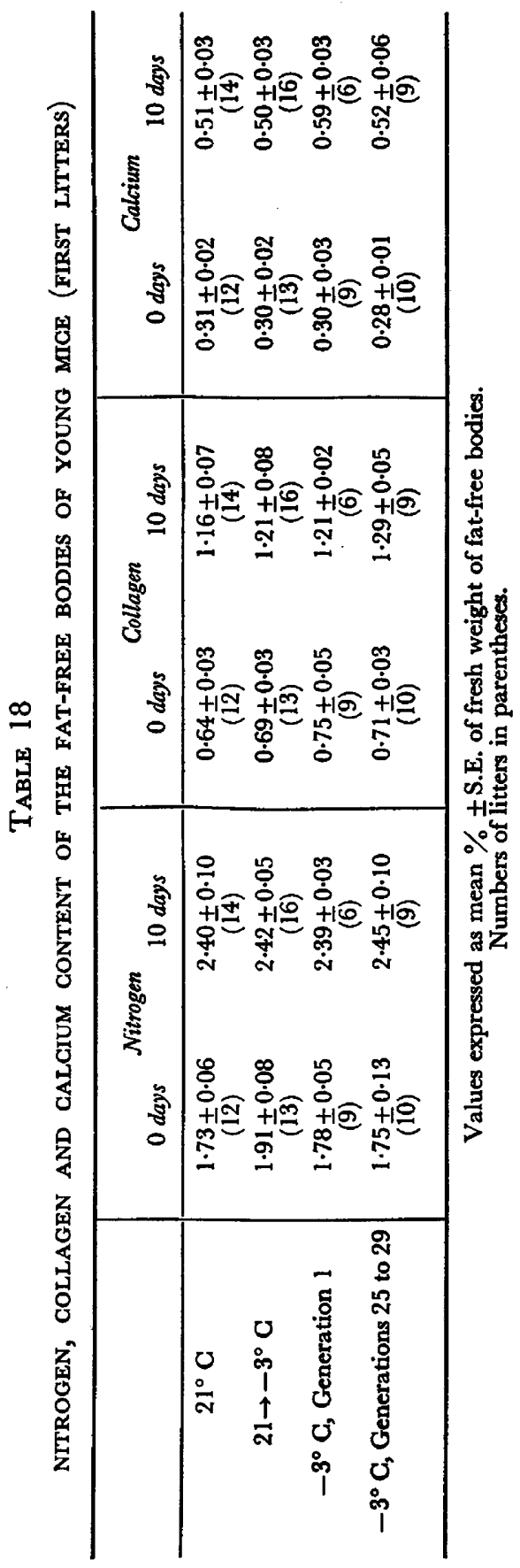




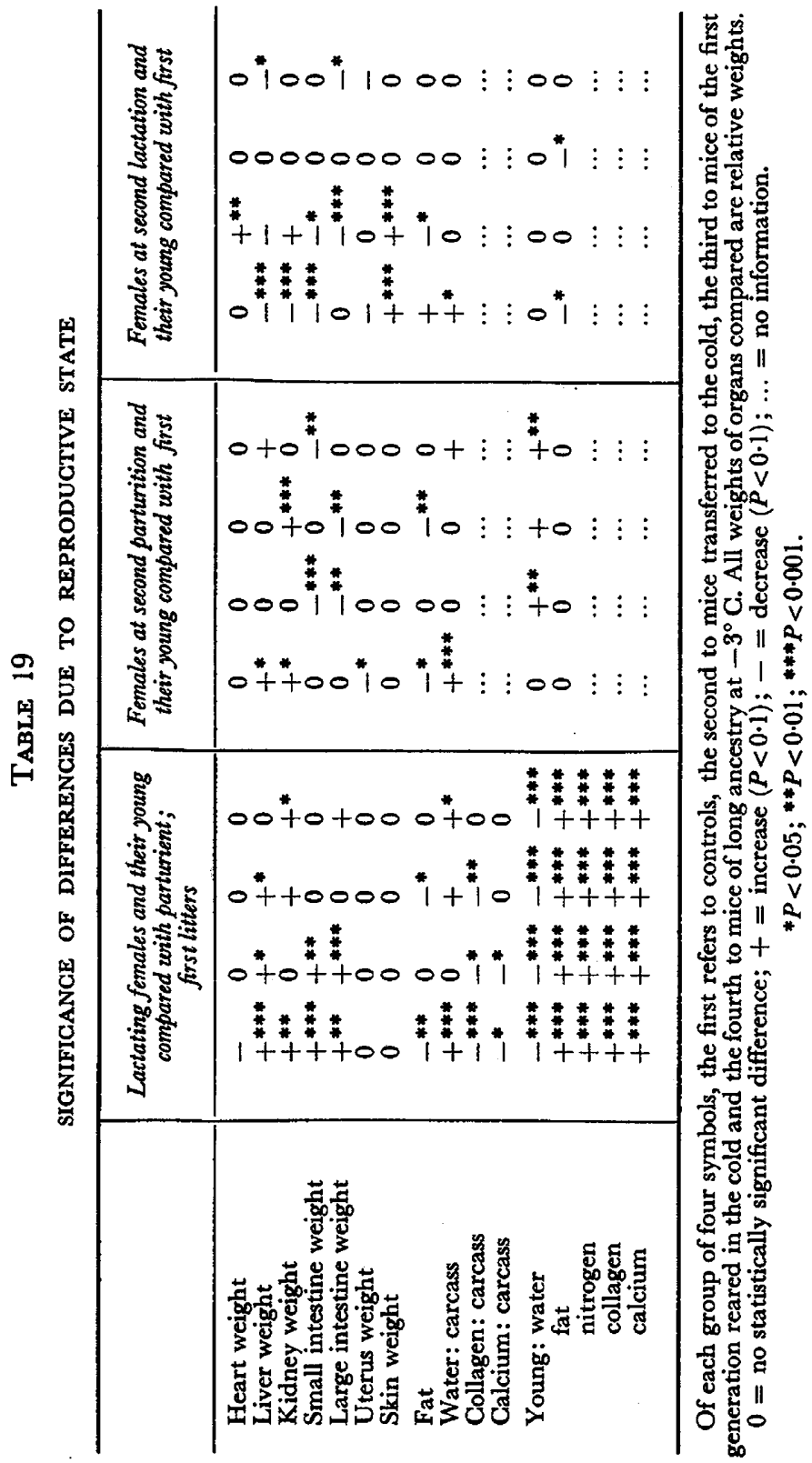




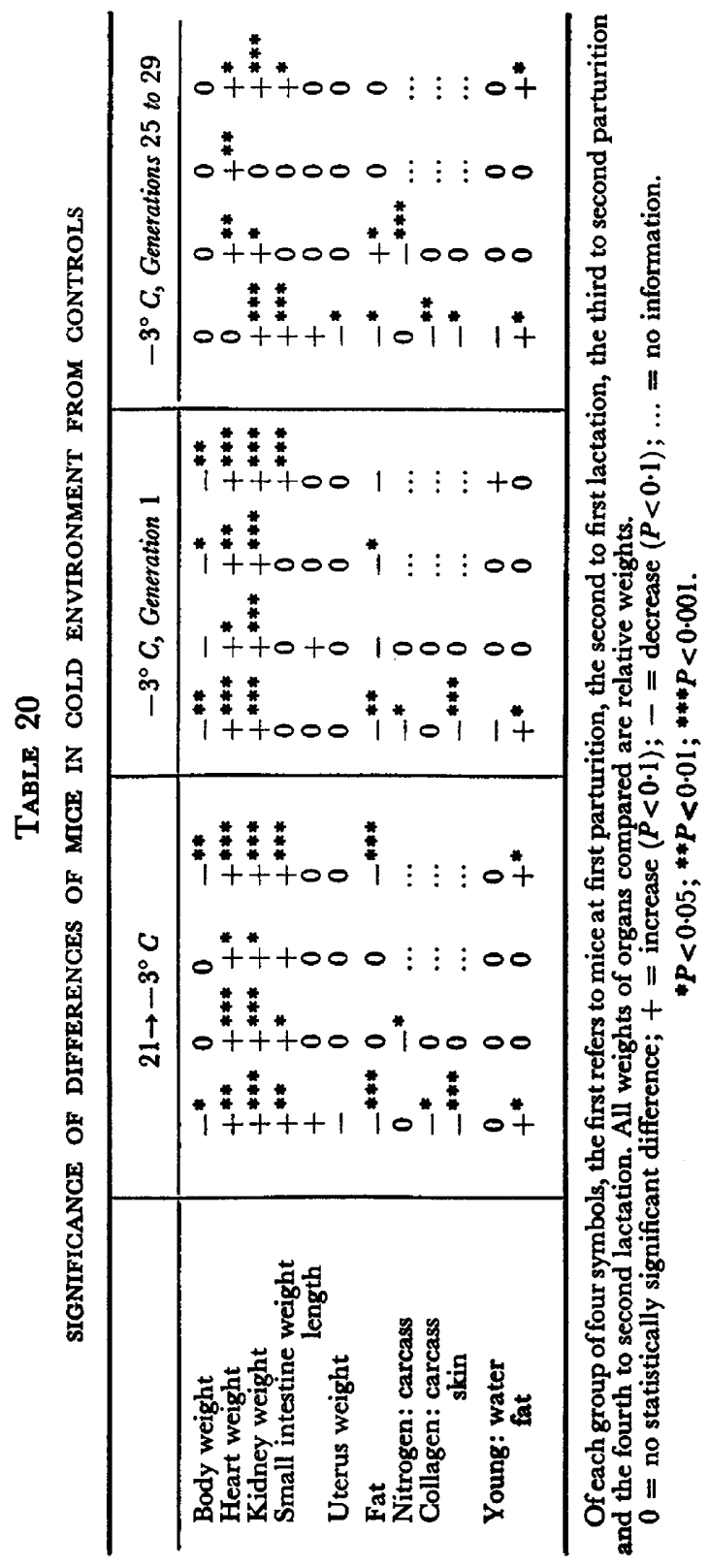


which occurs during the early days of lactation (Barnett \& Little, 1965). The changes during lactation may in fact be supposed to be responses to metabolic demand, especially since activity also probably rises during lactation: the time of minimum activity is around parturition (McEwan, unpublished data; see Barnett \& Burn, 1970). But, since metabolic turnover is highest during lactation, the largest changes might be expected then, and not during pregnancy. Probably the tissue hyperplasia and hypertrophy that take place during pregnancy reflect, in part, not metabolic demand but endocrine effects (reviewed by Dewar, 1969) and are, in effect, anticipating the needs of lactation.

\section{Effects of cold}

Differences attributable to the cold environment (Table 20) were also less marked than those of pregnancy, but generally agreed with those observed in unmated laboratory mammals (reviewed by Barnett \& Mount, 1967). Body weight was consistently lower in the cold than at $21^{\circ} \mathrm{C}$, and lowest among the mice of the first generation in the cold. This accords with previous observations (reviewed by Barnett, 1965) on the poor performance of mice reared by parents which had been transferred as adults to the cold environment. The relative heart weight was also consistently higher at $-3^{\circ} \mathrm{C}$; hence the effects of pregnancy and of cold on this organ were additive, and illustrate the extent to which it responds by enlargement to the demands put on it. Most studies of adaptive growth of heart muscle have used special experimental procedures or have involved forced, strenuous exercise (Grande \& Taylor, 1965); Jansky \& Hart (1968) have, however, recorded the increased cardiac output of rats exposed to cold. Like theirs, our observations illustrate the lability of the heart in its response to more natural demands.

The kidneys, too, were consistently larger at $-3^{\circ} \mathrm{C}$ than at $21^{\circ} \mathrm{C}$, in conformity with many other observations (Barnett \& Mount, 1967), though the kidneys of the mice of long ancestry in the cold were less affected than those of the other two groups. Unlike the heart, the kidneys did not enlarge during pregnancy but did so during lactation; hence, on this evidence, the kidneys respond to metabolic demand by enlargement, but not to the hormonal changes of pregnancy. Nevertheless, kidney function may have altered during pregnancy, since the mouse kidney can cope with added metabolic turnover without enlarging; in the previous study, the male mice did not have larger kidneys at $-3^{\circ} \mathrm{C}$ than at $21^{\circ} \mathrm{C}$ (Barnett \& Widdowson, 1965).

The small intestine also presented some anomalies. It was both heavier and longer in the cold, at least during first pregnancy and lactation; but in pregnancy it only lengthened, while lactation led to a consistent increase only in weight. Fell \& Campbell (1964) have reviewed work on the alimentary tract during lactation, especially that of mice, rats and ewes. The stomach, small intestine and caecum all become heavier, and decline after the young are weaned. Evidently, the gross effects of cold exposure and lactation are, in this respect, similar. On the evidence of Fell \& Campbell (1964), the hypertrophy of the intestine in both conditions is a local response to the presence of increased amounts of some constituents of food. The lengthened, thin-walled intestine of 
the period around parturition is subject to intussusception; and this is probably responsible for some deaths of mated females in our colony (K. M. H. Munro, unpublished data).

The most notable negative finding was the failure of the weight of the liver to reflect the increased metabolism in the cold, although virgin females at $-3^{\circ} \mathrm{C}$ have relative liver weights about $25 \%$ higher than those of controls (Barnett \& Widdowson, 1965). Evidently, the large increase during pregnancy enables the liver to cope, without further growth, with the extra demand imposed by a cold environment, as well as that arising from pregnancy.

\section{ACKNOWLEDGMENTS}

The work was aided by generous grants to S.A.B. by the Medical Research Council and the Royal Society. Indispensable statistical advice was given by Mr R. A. Elton. We are also very grateful to Miss J. M. Kendall, Mrs A. G. Neil, Mr R. G. Stoddart and Miss A. L. Walmsley for technical help.

\section{REFERENCES}

Angervall, L. \& Garlström, E. (1963) Theoretical criteria for the use of relative organ weights and similar ratios in biology. 7. theor. Biol. 4, 254.

Bailey, C. B., KitTs, W. D. \& Wood, A. J. (1960) Changes in the gross chemical composition of the mouse during growth in relation to the assessment of physiological age. Can. F. Anim. Sci. 40, 143.

BARNeTt, S. A. (1956) Endothermy and ectothermy in mice at $-3^{\circ}$ C. F. exp. Biol. 33, 124.

BARNETT, S. A. (1965) Adaptation of mice to cold. Biol. Rev. 40, 5.

Barnett, S. A. \& BURN, J. (1970) Maternal and infant behavior. In: Reproduction and Breeding Techniques for Laboratory Animals, p. 177. Ed. E. F. E. Hafez. Lea \& Febiger, Philadelphia.

Barnetr, S. A. \& Little, M. J. (1965) Maternal performance in mice at $-3^{\circ} \mathrm{C}$; food consumption and fertility. Proc. $R$. Soc. B, 162, 492.

Barnett, S. A. \& Mount, L. E. (1967) Resistance to cold in mammals. In: Thermobiology, p. 411. Ed. A. S. Rose. Academic Press, London.

BARNETT, S. A. \& WidDowson, E. M. (1965) Organ-weights and body-composition in mice bred for many generations at $-3^{\circ} \mathrm{C}$. Proc. $R$ Soc. B, 162, 502 .

Bruce, H. M. \& Parkes, A. S. (1949) Feeding and breeding of laboratory animals. 9. A complete cubed diet for mice and rats. F. Hyg., Camb. 47, 202.

DEWAR, A. D. (1969) The mechanism and nature of the extra-uterine weight gain of pregnancy in the mouse. F. Reprod. Fert. Suppl. 9, 17.

Dickerson, J. W. T. (1962) The effect of development on the composition of a long bone of the pig, rat and fowl. Biochem. . . 82, 47.

Fell, B. F. \& CAMpbell, R. M. (1964) Gastrointestinal hypertrophy in lactation and its relation to diet. In: The Role of the Gastrointestinal Tract in Protein Metabolism, p. 199. Ed. H. N. Munro. Blackwell Scientific Publications, Oxford.

Grande, F. \& TAYloR, H. L. (1965) Adaptive changes in the heart, vessels, and patterns of control under chronically high loads. Handb. Physiol. 3, 2615. Ed. W. S. Hamilton. American Physiological Society.

JANSKY, L. \& HART, J. S. (1968) Cardiac output and organ blood flow in warm- and cold-acclimated rats exposed to cold. Can. F. Physiol. Pharmac. 46, 653.

Kennedy, G. C., Pearce, W. M. \& Parrott, D. M. V. (1958) Liver growth in the lactating rat. $\mathcal{F}$. Endocr. 17, 158.

Pennycuik, P. R. (1966) Differences between mice gestating and lactating at $21^{\circ} \mathrm{C}$ and at $34^{\circ}-36^{\circ}$ with particular reference to the mammary gland. Aust. F. exp. Biol. med. Sci. 44, 419.

Peters, J. M. \& Krijnen, C. J. (1966) Organ weights and water contents of lactating rats. Growth, 30, 295.

Peters, J. M., KRIJNen, C. J. \& Boyd, E. M. (1967) Role of concepta in the production of hypertrophy and hydration of maternal body organs in the third week of pregnancy in albino rats. F. Reprod. Fert. 14, 235.

SPRAY, G. M. (1950) A study of some aspects of reproduction by means of chemical analysis. Br. $\mathcal{F}$. Nutr. 4, 354. 
SPRAY, C. M. \& WidDowson, E. M. (1950) The effect of growth and development on the composition of mammals. Br. F. Nutr. 4, 332.

Stoddart, R. C. (1966) Ice blocks as water supply for mice at $-3^{\circ}$ C. F. Inst. Anim. Techns, 17, 158.

Widpowson, E. M. \& Dickerson, J. W. T. (1964) Chemical composition of the body. In: Mineral Metabolism, Vol. 2A, p. 1. Eds. G. L. Comar and F. Bronner. Academic Press, New York. 